\title{
Environmental and Behavioral Modeling of Mitigating Light Pollution: Implication for a Better World
}

\author{
Bassam Hamdar ${ }^{1}$, Elie Meouchy ${ }^{2,} \&$ Zeinab Hamdar ${ }^{3}$ \\ ${ }^{1}$ Department of Economics, Faculty of Business Administration, Al Maaref University, Beirut, Lebanon \\ ${ }^{2}$ Faculty of Business and Economics, American University of Science and Technology, Beirut, Lebanon \\ ${ }^{3}$ School of English, Drama and Creative Studies, University of Birmingham, Birmingham, UK \\ Correspondence: Bassam Hamdar, Dean, Faculty of Business Administration, Al Maaref University, Beirut, \\ Lebanon.
}

Received: February 4, 2021

Accepted: March 26, 2021

Online Published: April 1, 2021

doi:10.5430/ijba.v12n3p12

URL: https://doi.org/10.5430/ijba.v12n3p12

\begin{abstract}
Light has always fascinated humans, thus they used to burn different materials to illuminate their indoors and outdoors as well at night for better visibility and safety. Nighttime lighting has rapidly proliferated throughout the cities and has kept the darkness away. Artificial light, which has become a necessity, contributes to the so-called Light Pollution. Light pollution is therefore a crucial aspect for lighting designers to consider while designing. Knowing how to accomplish 'good' lighting is considered a characteristic, and a distinctive skill of lighting professionals. The objective of this study is to highlight the causes behind light pollution, the groups that are contributing to its existence, and to identify ways and means for avoiding it. To achieve the objective of this study, the following three questions were adopted: What produces light pollution? How could light pollution be reduced? Finally, are lighting design companies helping in light pollution mitigation? A survey of lighting professionals was adopted to trace out the main causes of light pollution. The results show that lighting professionals are considered as the main responsible factor for light pollution, and play a major role in its mitigation.
\end{abstract}

Keywords: environmental and behavioral modeling, light pollution mitigation, artificial lighting, light professionals

\section{Introduction}

Light has always fascinated humans, thus they used to burn different materials to illuminate their indoors and outdoors as well at night for better visibility and safety. However, ever since the first light bulb, the use of artificial lighting has accelerated dramatically. Nighttime lighting has rapidly proliferated throughout the cities and has kept the darkness away. Artificial light, which has become a necessity, contributes to the so-called Light Pollution. Light pollution is unwanted, inefficient, annoying or unnecessary artificial outdoor lighting. It consists of many negative effects such as sky glow, glare, light trespass, light clutter, shortage visibility at night, and energy waste. Scientists have provided convincing evidence that ties artificial lighting to several issues related to human health, the ecological wellbeing, and the global ecological system (Bermudez, 2021).

Light pollution is therefore a crucial aspect for lighting designers to consider while designing. Knowing how to accomplish 'good' lighting is considered a characteristic and distinctive skill of lighting professionals (Insulander, 2012).

It is obvious that light is essential for any living organism on the planet. All living things need natural light to survive including human beings. The first time the humankind experienced a period of light, known as daylight, was by sunlight, and periods of darkness in night times. Natural light is a natural resource that humans depend on to survive, and it largely controls their circadian rhythms; in addition, it has enabled us to live productive lives and to do so many daytime activities. Moreover, darkness has always been a major element of the natural behavior of animals, especially, the nocturnal ones. Both light and dark are necessary for the health of humans, animals, and plants (Slade, 2018).

Humans by nature are diurnal creatures who have tried many methods to illuminate the night insuring a safe environment from strangers and for better visibility at night. Thus, they were burning different materials to produce what is called an artificial light, and this was to supplement the existing light as to improve visibility in their built 
environment. Fire was mainly used as a source of outdoor lighting followed by many lighting technologies — candles, oil lamps or gas lighting - that have been designed by people to illuminate their indoors and outdoors as well at night. People started to be rid of the old habits and stopped being afraid to go outside at night, and began increasingly staying out later than before. At that time, in the mid-nineteenth century, the term "nightlight" came into use (Brox, 2015).

Now, relatively the recent invention is lighting that is powered by electricity. Many studies and researches about electricity were first conducted in the early $17^{\text {th }}$ century until the first electric light bulb was invented/designed by Thomas Edison in 1879, and the world turned to be brighter ever since. Since then, the artificial lighting field has been increasingly developing and the lighting manufacturing industry has been changing fast in the last few years. Electrification quickly reduced the lack of urban illumination, as it has been widely expended during the twentieth century along with the urbanization, the growth of population, and transportation networks (Encyclopedia Americana Corp, 1918).

Light pollution, which is also known as photo pollution, is extravagant, misdirected and nosy unwanted artificial light. It consists of many negative effects such as sky glow, glare, light trespass, light clutter, shortage visibility at night, and energy waste. Light pollution has received much attention in recent years due to its negative properties, which affect the astronomers and has serious effects on human and wildlife health. Light pollution is considered as the ubiquitous type of environmental pollution (Khan, 2017).

\section{Need for the Study}

Many scientists have determined that light pollution is increasing globally, this goes on both the developed and the developing countries levels. It has always been believed that light pollution growth interrelates with the growth rates of population. In other words, whenever the population is growing the need for outdoor lighting becomes higher which is eventually, to some extent, lead to light pollution, especially, when using poor nighttime lights (Drake, 2019).

Many outdoor lighting sources produce light pollution such as streetlights that are always on, and the security floodlights that are turned on at night. Another source comes from building facade lighting, led screens, manufacturers, offices, landscape lighting, and illuminated sports facilities (Bermudez, 2012). However, although the causes of the light pollution have been demonstrated over many years ago, little attention has been given to the role of lighting design companies in this matter. Many researchers have made several discussions on how to reduce light pollution by minimizing the energy consumption, glare, light trespass .But only few have suggested how lighting consultants can shorten the way, and avoid over illumination consequences. Lighting design professionals can help in diminishing the excessive unwanted artificial light the first day they manage a lighting design project, through the concept to the execution phase. At the end, this might influence the growth rate of light pollution (Karol, 2010).

\section{Problem Definition}

Light pollution is a new type of environmental damage that threatens the world around us. We, humans, cause this by neglecting the safety and comfort, even not thinking of the consequences. However, many concerned parties might be able to think closely of these consequences from their perspective, and help avoiding the exposer to such negative effects. These concerned parties include all the lighting manufacturers, lighting engineers and specifically the lighting designers (Hussein, et al, 2020).

Few studies have focused on the responsibility of lighting design companies that are able to protect the environment from the light pollution threat. It has been indicated that trying too hard to partially reduce the previously mentioned causes that lead to light pollution, is not successfully implemented. However, designing and implementing a strategy, which enables the lighting specialist to design and control the projects taking into account all the safety aspects, would be a quantum leap in the lighting field (Kuhun, 2012).

\section{Objective of the Study}

The objective of this research is to highlight what is known as light pollution, the topic that most of the people have never heard of it before. This paper also examines the reasons behind light pollution; identify the concerned groups who contributed to its existence, and find convenient solutions. Furthermore, this paper will answer the following questions:

1-What produces light pollution?

2-How can light pollution be reduced?

3-Are lighting design companies helping in light pollution mitigation? 
Moreover, the following hypotheses are adopted by the study to shed light on the ways and means to reduce light pollution:

H1: Poor lighting design can produce light pollution.

$\mathrm{H} 2$ : Light pollution can be decreased by implementing an effective control system for outdoor lighting.

H3: Light pollution mitigation is the mission of lighting professionals.

\section{Literature Review}

Looking around one finds many things surrounding us including trees, clouds, rocks, animals etc. We can never be solitary people; we cannot be alone on this planet. Our earth contains millions of different organisms and many things surround every organism, like other organisms, water, plants, light, air, mountains, etc. An environment is put together by all living and non-living things which surround any organism. "Climate" is a word derived from the French word "Climate" which means "World". In our surroundings, the biotic factors include human beings, animals, plants, microbes etc. and abiotic factories such as air, soil, water, light etc. (Edwards, 2019).

The World consists of variant items surrounding man and the living species. It consists of land, air, water, and the interdependence, which exist among and between land, air and water and human beings, and other living creatures such as animals, plants and microorganisms. It is a whole system that cannot be separated, which contains biological, cultural, physical, and social elements that are interconnected in countless ways i.e., individually and collectively (Kalavathy, 2004).

The environment consists of four interlinked systems known as the lithosphere, atmosphere, hydrosphere, and biosphere. These four systems are constantly changing, and these changes influence-and in turn are influenced by-human activities and their environment .In other words, the interaction networks that exist, in some situations, between these various structures and human activities, are extensive and highly complex (Kumarasamy et al., 2004).

\subsection{Components of the Natural Environment}

As stated earlier in this paper, the natural world is subdivided into four key components, categories or spheres such as the lithosphere, the atmosphere, the hydrosphere and the biosphere. They are systems themselves, and they overlap and interact tightly with each other. It is important to know that human activities often affect those four components. The four structures can be briefly addressed in the following manner.

\subsection{Lithosphere}

Lithosphere is the portion of the earth that is made of minerals and rocks; it is forming the planet's crust. This forms a layer of earth's rocks, soil, mountains etc. (National Geographic Society, 2015).

\subsection{Atmosphere}

A thin layer on the one hand protects the human beings and the solid planet from dangerous sunlight radiations, and on the other hand warms the surface of the earth. Furthermore, the atmosphere is a membrane that includes vital substances for life, such as carbon, oxygen etc. (Kalavathy, 2004).

\subsection{Hydrosphere}

Hydrosphere consists of all bodies of water, water in its liquid phase such as ponds, streams, lakes, rivers and the oceans and seas of the earth etc. In addition to its solid phase when it is ice, the water in its gaseous phase such as vapor also (National Geographic Society, 2015).

\subsection{Biosphere}

All organisms, which live on the surface of the Earth and interact with air and water, are considered under the framework of the biosphere. Biosphere contains all the animals, plants and microorganisms, from the smallest microscopic organism to the largest marine mammals in the world. In addition to the factors of the physical environment, biosphere includes the social environment, which shows how human groups have organized themselves and how they work to meet their needs (Kumarasamy et al. 2004). Figure 1, shows the Earth's environmental spheres. 


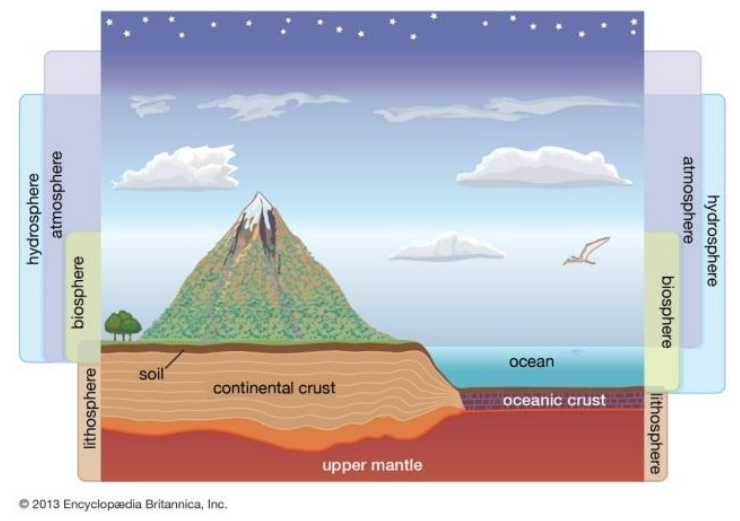

Figure 1. Earth's environmental spheres

Source: https://www.britannica.com/science/hydrosphere

The above-mentioned components are key components of the earth system, which interconnect with each other through energy and material pathways. In addition, the vast majority of the energy supplied in the earth system comes from the sunlight that is considered the main element in the process of earthly ecosystems. In addition, to the natural light provided by the sun, the quality of night sky is also a factor that protects the natural landscapes and their natural values and reinforces the mission to protect nature in general (The Mizon, 2012).

\subsection{Nature}

All that human beings depend on for survival comes from features contained within the four spheres of the Earth that are considered natural resources. Humans cannot add to them but they have expanded their potential uses widely. When we discover something, we can use it or profit from it, we instantly harass to get it. In addition, it becomes a natural resource. Any natural element that has the potential to be used is a natural resource (Gritzner, 2010).

\subsection{Natural Light}

Natural light is a natural source of light that cannot be controlled and can be found in nature in terms of intensity, direction, and amount of light. (Jill Harness, 2019). There is normally one source of natural light-the Sun, which is considered to be the main source of daytime light, in addition to the moon which reflects a certain amount of nighttime sunlight (Kronfeld-Schor \& Dayan, 2003; Gerrish et al., 2009).

The sun is not considered the key light but a creature of the natural ambient light. The sun is a renewable resource of light, energy, heat, and vitamin D; it is the earth's source of life. This natural light allows us to realize spaces, recognize rhythms and movements, and perceive distances (Neff, Fankhauser \& Chory, 2000; Ragni \& D'Alcal'a, 2004).

By improving efficiency, well-being and rest, the sun's natural lighting cycle is known for its powerful and balanced energy. (Robert Karlicek et al. 2017). Nevertheless, the more lighting technologies develop and the growth of cities continues, the more natural light regimes are modified by space, time, and wavelengths exceeding dark refuges (Aubrecht et al. 2010).

\subsection{Built Environment}

The natural environment contrasts with the built environment, which includes areas and components strongly influenced by people. We all build, and therefore make important contributions to the built environment. From one experience to the next, we design and build our lives. Components of the built environment emerge from human needs, thoughts, and actions based on those experiences (Bartuska, 2007).

The term built environment for example, is an integral part of a new definition of landscape architecture, which the International Federation of Landscape Architects approved in 2003. Tasks deemed fundamental to their work include 'planning, designing, managing, preserving and controlling functional and esthetic configurations of built environments' and 'identifying and creating suitable solutions for the quality and use of the built environment (IFLA News, No. 48, 2003). 
The built environment's diversity and scale, its complex content, and its subtle meanings are grouped into seven interrelated components: objects, interiors, structures, ecosystems, towns, regions, and Earth. The sum of the seven defines the extent of the total constructed environment (Bartuska, 2007).

\subsection{Artificial Light}

Since the earliest times, the Sun, Moon, and Stars have been our natural lights. We have learned to harness and domesticate fire, and we filled our homes and streets with artificial lighting a lot more recently. The amount of sunlight that the Moon reflects away is small compared to what falls on it. The Moon's albedo is 0.7 on a scale of 0 to 10 , representing only 7 percent of the reflective capacity. However, even this weak ration of nighttime light was adequate to allow human activity to proceed under the Moon, after sunset, before artificial lighting (Mizon, 2002).

In pre-industrial times, artificial light was generated by burning various materials, including wood, oil, and even dried fish. Although those lighting methods definitely had a local impact on animal behavior and ecology, these effects were minimal. However, the nighttime environment has been transformed by electric lights over significant portions of the Earth's surface (Longcore \& Rich, 2004).

One relatively young discipline is the scientific application of artificial lighting. Unlike daylighting, which looks back on a practice that has slowly evolved over several thousand years, the need to create ideas for artificial illumination has only become a necessity in the last or two decades. Just 200 years ago planning using artificial light sources was confined to deciding where best to position the few candles or oil lamps available (Harald \& Rüdiger, 1992).

Light is a requirement for a healthy human life, efficiency and health. Rather than ever, modern humans rely on artificial light for a large part of the day. Although artificial light improves convenience, excessive exposure to artificial light can have negative impacts on ecosystems and on human health (Gaston et al., 2015; Haim \& Zubidat, 2015).

\subsection{Light Pollution}

Light has played an integral role in the way of life of humankind throughout history, shaping the ideology and providing a means for basic survival. Many faiths focus on light as being fundamentally good. The Bible's first chapter states, "God said, 'Let there be light,' and there was light. In addition, God saw that the light was good: and God separated the light from the darkness. Moreover, God called the light Day, and the night he called Niht (old English for night). "In his early days, the source of illumination for man-kind was mainly the moon, the stars, and the sun. This progressed with the artificial production of illumination by fire and torches, oil lamps and candles, and eventually gas lamps, light bulbs, and streetlights (National Geographic Society, 2015).

There is no question of the need for outdoor lighting to make our nighttime environment more effective. However, too much of the lighting installed to try to meet this need, compromises the purpose and adversely affects the nighttime environment, including our view of the stars and the universe above us (ibid). Figure 2, shows a Schematic graph showing the interrelation between the environments, lighting manufacturers, and lighting design (Light pollution shows up as result of overlap of the three subjects).

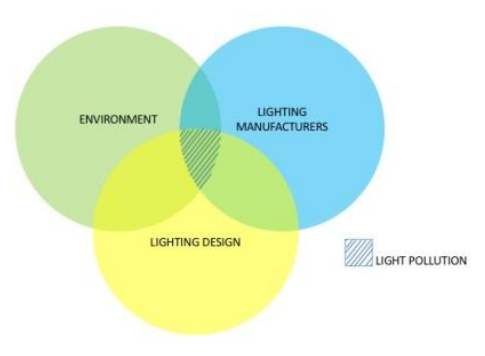

Figure 2. Light pollution

\subsection{What Is Light Pollution?}

Light pollution is a relatively recently defined environmental problem, and can appear to be an insignificant concern in some of its manifestations (Taylor,2007\& Stone, 2017).Light pollution is a major concern of professional and 
amateur astronomers alike. Astronomers need dark skies to study objects, which are very faint. The professional astronomical community has been in the forefront of light pollution research as it is in their best interest to see this problem curtailed or eliminated. Crawford (2001) has noted in his paper (Light Pollution), that light pollution has been recognized as an issue since the 1920s. The article further points out that light pollution was increasingly seen as a threat to the profession of the astronomers in the early 1970s. Although professional astronomers are only a small fraction of the general population, it is assumed that artificial light was first considered a concern because of their exposure to this issue. One of the negative side effects of artificial outdoor lighting is light pollution. The problem comes when we choose to do the illumination with a poor choice of lighting fixture or installation for whatever reason. Too much of the worldwide nighttime lighting is of poor quality, poor design or without any design at all (Crawford, 2001). The word light pollution is an unpleasant one but as there seems to be no better option, it will be used here (Narisada \& Schreuder, 2004).

Wherever it is needed, the light should come. If not, it is 'spilled', and it causes economic losses in electricity and light pollution (Schreuder, 1995). Estimating the amount of money and energy involved in light pollution is not easy, but the amounts are considerable (Narisada \& Schreuder, 2004). Some consider the visual confusion and pain, as well as harm to the atmosphere, as more severe. With the modern enlightened era, large parts of the world have been swathed in artificial light just in the last 100 years. The use of artificial light at night (ALAN), and the related brightening of the nightscape have increased worldwide by more than 2 per cent per year (Kyba et al. 2017; Hölker et al. 2010).

Figure 3 shows how cities are cutting down on light pollution.

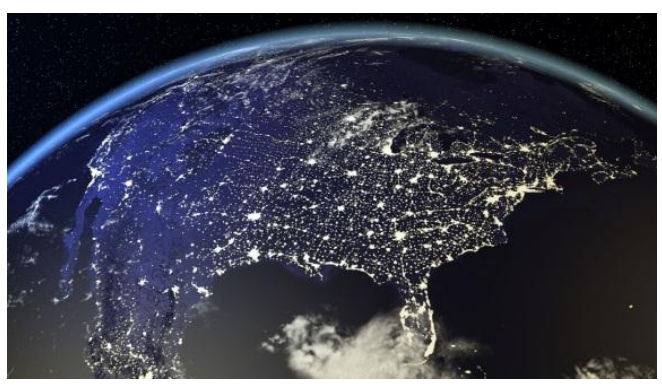

Figure 3. How cities are cutting down on light pollution

Source:

https://www.axios.com/how-cities-are-cutting-down-on-light-pollution-19875aff-4cee-40ad-bfeb-7f0a83c3d816.html

The US, UK, Germany, Netherlands, Spain and Italy are some of the brightest states of the world and the highest in light pollution. Cinzano et al. (2001) indicated that $18.7 \%$ of the ground surface of the earth is prone to extensive night sky brightness. It is believed that light pollution growth interrelates with the growth rates for population. In other words, whenever the population is growing the need for outdoor lighting becomes higher which eventually leads to light pollution. In fact, more than $80 \%$ of the world lives under light polluted skies, while $99 \%$ of the people living in Europe and the United States are affected by it. Moreover, one third of humanity can no longer see the Milky Way - the closest and brightest galaxy to the Earth (Kane, 2016).Eastern Europe was out of the entire quick light pollution growth rate that occurred, because it experienced economic troubles and government breakdown in the 1990s. In addition, parts of Northern Italy were out of this growth since they created and applied lighting regulations (Falchi, 2011).

The light pollution problem has been vividly witnessed across the Middle East region, and it is a major factor of losing connection with the cosmos, which is affecting the health and environment of the entire Mideast area. Only few stars in addition to the moon are visible over many countries in the Middle East i.e., Kuwait, Qatar, United Arab Emirates, and Saudi Arabia, due to the glare of artificial luminance. This makes these countries the most light-polluted places on earth after Singapore.

In Lebanon, one can clearly see light pollution in Beirut and many other cities where there is an excessive use of artificial light. In addition, this affects some of the Lebanese villages where light pollution reached their dark skies, and lead to a great loss in the stunning night scenes and the unique night sky (Nader, 2012). 


\section{Research Methodology}

\subsection{Quantitative Research}

The main objective of this research paper is to attain a complete understanding of the environmental problem, which is light pollution, the topic that most of the people have never heard about before. Therefore, this paper intends to uncover the extant to which people and/or consumers are aware of in regards to light pollution, and what the best ways to limit it are. Another research objective of this paper is related to the role of lighting professionals in light pollution mitigation. Using a quantitative research method will reveal the proportion of lighting designers that are environmentally conscious and aware of light pollution.

\subsection{Target Population}

In order to achieve the aim and objectives of this research, a combination of two research methodologies have been utilized. One methodology is a survey. The survey is divided into two different questionnaires and a different target population for each. The survey is utilized to quantitatively study the extent to which the public in general, and the lighting specialists in specific, are aware of light pollution and its effects.

The survey of the consumers-users' questionnaire covers the Lebanese population focusing on the age group between the 18 and 60 years of age. As for the lighting professionals' questionnaire, it required different population from different geographical and cultural locations, i.e. lighting practitioners from around the world between the ages of 25 and 70 years (since Lebanon has a very small population of light professionals and light designers).

The Sample consisted of 1043 of consumers-users and 1519 of professionals and designers. The total sample size is 2562.

\subsection{Qualitative Research}

Further to the quantitative method used in this paper, a qualitative approach is solicited to achieve the objectives of the research. Considering that, the opinion of the lighting experts about light pollution is important and relevant to the subject at hand, a focus group/one-on-one discussion was chosen as a research method to collect the qualitative data. The focus group was conducted with eight leading experts (practitioners and designers).

\section{Results and Findings}

\subsection{Quantitative Results and Analyses}

The results are divided in two sections: Consumers-users and Lighting professional's results.

This part explains the results related to each of the two conducted separately questionnaires.

\subsection{Consumers-Users Questionnaire Results}

\subsubsection{Descriptive Survey Results}

This section explains the descriptive results related to the consumers-users' questionnaire describing the main sample characteristics and basic descriptive findings.

The participants were asked to describe the view of the sky at night from their living location. Figure 4, shows that $28 \%$ of the population cannot see any stars in the area where they live. A 51.9\% can see some stars but not the Milky Way. Therefore, the higher the percentage of the people who live in urban and suburban areas, the higher the number of people who cannot observe any stars at night rises.

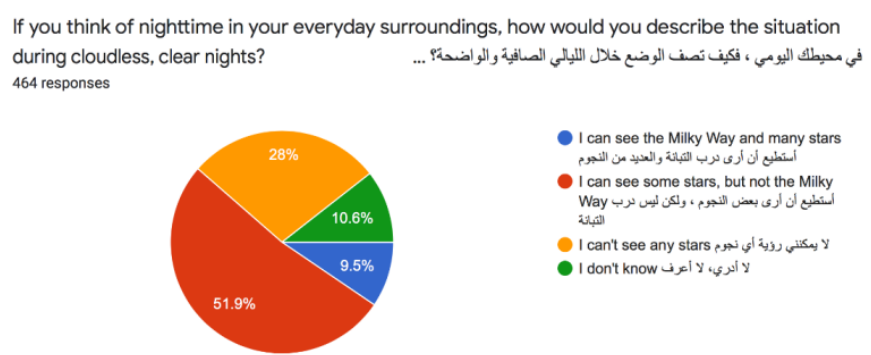

Figure 4. Graph explains the view of the night sky from the respondents' place of residence 
Are you...?

464 responses

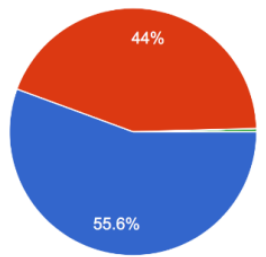

Figure 5. Gender of the participants

Figure 5 shows that the population of the questionnaire is divided into $55.6 \%$ of females and $44 \%$ of males.

Figure 6 indicates that $64.3 \%$ of the respondents of consumers-users' questionnaire are interested in environmental issues i.e., $24.4 \%$ are extremely interested, $39.9 \%$ are very interested, and $33 \%$ are somewhat interested.

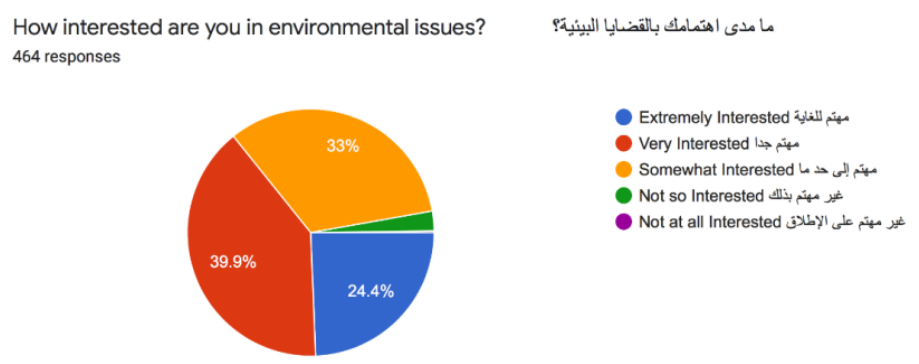

Figure 6. How the respondents are interested in environmental issues

\subsection{Inferential Survey Results}

This section explains the inferential results related to the consumers-users' questionnaire describing the nature and the results of the statistical tests.

The results of the respondents of consumers-users' questionnaire, indicated that $55 \%$ have never heard of light pollution before; $30.6 \%$ responded with 'no', and $24.4 \%$ with 'just now, interestingly, there is a significant number of people who have heard of light pollution before i.e., $45 \%$ (Figure 7).

Have you ever heard of light pollution? 464 responses

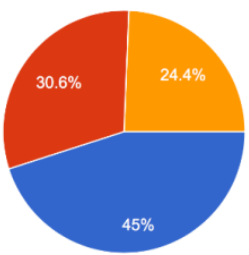

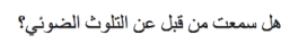

Yes ن إ

№y

الأن فتط ، من Just now, through this survey خلال هذا الاستطلاع

Figure 7. Shows the percentage of people who have/never heard of light pollution

Figure 8, is related to how important the participants see light pollution compared to other environmental issues. In addition, $69 \%$ of the respondents consider that light pollution is equally as important as other environmental issues. However, 25.5\% consider it as less important. The rest of the percentages are almost negligible. 


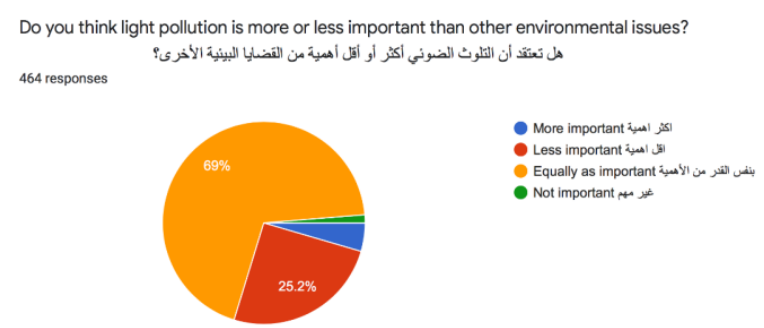

Figure 8. How important do the participants consider light pollution compared to other environmental issue

According to the data provided by the consumers-users' questionnaire, the majority of people do not know that light pollution even exists. Moreover, among those who have heard of it before, few of which are aware of its causes and effects

\subsection{Lighting Professionals Questionnaire Results}

\subsubsection{Descriptive Survey Results}

This questionnaire is based on the feedback of 260 professionals; their light-related activities are divided as follows: the majority work in Architectural and Decorative Lighting Design they constitute about $87.7 \%$ of all participants. Functional light planning $44.6 \%$ and Development of urban lighting concepts/master plans $31.2 \%$ (Figure 9).

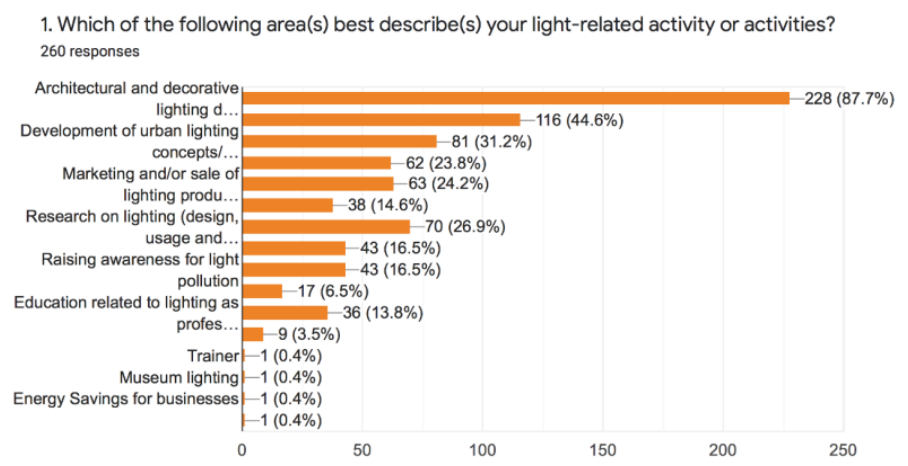

Figure 9. Professionals' light-related activities

\subsection{Inferential Survey Results}

This section explains the inferential results related to the consumers-users' questionnaire and tests the hypotheses that describe the nature and results of statistical tests.

Since the early 1970s, the concept of light pollution has been identified, but it has clearly become a point of discussion only in recent years among lighting professionals. The results show that $34.2 \%$ of all participants heard about light pollution 10 years ago, and $34.2 \%$ of all participants heard of it 6 years ago, and only $28.1 \%$ heard about light pollution 2 years ago (Figure, 10).

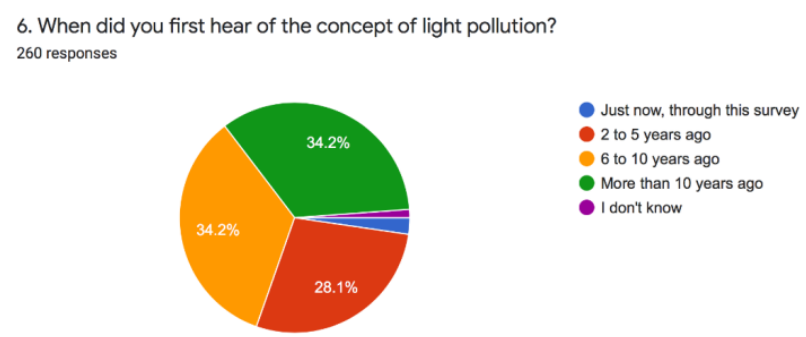

Figure 10. First time lighting professionals heard of the concept of light pollution 


\subsection{Qualitative Results and Analysis}

This section explains the outcomes of the qualitative study resulting from one focus group of eight people and many one-on-one discussion sessions with lighting professionals. The participants were asked to give a recommendation of a lighting application that avoids or reduces light pollution. The responses are as follows:

1-Avoid directing outdoor fixtures upwards and use them with a proper light intensity.

2-Lighting designers should take into consideration good positioning of the lighting fixtures. 3-Use of accessories to reduce the glare is needed, selection of a proper light beam optics, and the use of the appropriate light intensity and color temperature is necessary.

4-The replacement of the current light poles with low-level light bollards along with upward light cutoff, is needed for preventing light from spilling to unwanted areas is recommended.

5- The use of sensors and smart light control systems by setting a clock and operating times for lighting projects, , Lighting installations where all the fixtures are fully shielded and glare-controlled (e.g. bollards, down- lights, wall sconces), and only lighting the surface that needs to be lit with minimum reflection towards the sky.

Furthermore, the participants were asked if they do actively take precautions/actions to avoid or reduce light pollution in their light-related activities. Most of their Reponses were in line with using practices to reduce light pollution.

\subsubsection{Hypotheses Testing}

The following hypotheses on which this paper is based are examined and validated. The first hypothesis is as follows:

H1: Poor lighting design can produce light pollution.

The ability of seeing the stars at night is linked to the amount of artificial light used at night in the place of residence. Results show that people who cannot or barely see the stars in the sky at night live in urban or suburban areas. The fact that these areas are overpopulated, the demand for artificial lighting at night increases for safety purposes.

The second hypothesis is:

$\mathrm{H} 2$ : Light pollution can be decreased by implementing an effective control system for outdoor lighting.

The results show that the most affected elements by excessive artificial outdoor lighting are the ecosystems (animals and other organisms), and human's sleep (due to light trespass). The latter takes place when we do not use light efficiently where and when it is needed.

The third hypothesis is:

H3: Light pollution mitigation is the mission of lighting professionals.

The participants were asked to indicate the group, which is responsible for avoiding, or reducing light pollution, the majority indicated that lighting designers and planners are the main responsible for lighting pollution mitigation.

\section{Conclusion and Recommendations}

\subsection{Conclusion}

Human beings, who belong to the natural environment, depend on natural light given for granted as a natural resource by the sun. That light, which has been used for surviving and doing daytime activities, has never been sufficient to lengthen the day and work overnights. Therefore, people have recreated activities that involve light. They started to illuminate the built environment using artificial lighting. Since then, the artificial light has changed dramatically, and it is no longer a temporary expedient but a form of lighting design to be taken seriously, ranking with natural light. The outdoors and public areas were lit to improve visibility and insure safety at night. Back then, lighting was unorganized and used in an adoring way that created an excessive artificial nighttime lighting, which in turn led to light pollution. However, few years ago, awareness of specific groups and specialists started to spread around creating a base for reducing light pollution.

The objective of this study is to map out the causes behind light pollution, the groups that are contributing to its existence, and to identify ways and means for avoiding it. To achieve the objective of this study, the following three questions were adopted: What produces light pollution? How could light pollution be reduced? Finally, are lighting design companies helping in light pollution mitigation? A survey of lighting professionals was adopted to trace out the main causes of light pollution. The results show that lighting professionals are considered as the main responsible 
factor for light pollution, and play a major role in its mitigation. Moreover, it has been shown that controlling the artificial light spill to the task area where it is needed is an effective way to avoid light pollution. In addition, controlling the ways of using light control systems and the schedules to adjust the light as per the requirements of each project is very helpful. In conclusion, light is something intangible but it is controllable, identifying when light is a source of pollution, and how to avoid it, and which group should address it, when all of such concerns are taken seriously, then and only then, light pollution will be no more a big issue.

\subsection{Recommendations}

Lighting professionals must be more environmentally concerned and be aware of all the issues in order to help in preserving the environment. Lighting professionals should consider light pollution when designing and planning lighting projects. Lighting specialists should deliver good lighting design projects with proper anti-glare systems, color temperature and precision optics to avoid light pollution, and to preserve the night. This will also aesthetically enhance the lighting effects. Lighting companies should introduce light pollution subject in their training programs, so their trainees will be able to share this culture among each other in the working environment. Moreover, lighting firms should make their clients aware of light pollution and its negative effects. It is clear that the current regulatory framework is inadequate in respect to LED technology, and needs to be urgently adapted to eradicate the problems associated with current designs of LED fixtures.

\section{Limitation of the Study}

This study focuses mainly on how lighting design companies around the world can help in light pollution mitigation, and how the lighting companies are dealing with this environmental problem. The study should extend to cover the role of the public sector and the regulatory branches to mitigate light pollution. Another limitation is the availability of data regarding light pollution, since this subject is not well known among many in the present day.

\section{Future Research}

Future researchers shall tackle light pollution topic in depth and consider it as equally important as other environmental issues. Researchers should spread awareness about light pollution through their published online research for the public use. Researchers should also address light pollution in other aspects and perspectives such as billboards lighting, led screens, concerts and festivals lighting, and car floodlights/headlights that might produce light pollution as well. Finally, researchers should examine low-level lighting and dimmed lighting approach in lighting design projects, and see how it may positively or negatively contribute to light pollution mitigation.

\section{References}

Aubrecht, C., Malanding, J., \& Sherbinin, D. A. (2010). Global assessment of light pollution impact on protected areas. Retrieved from http://www.ciesin.columbia.edu/publications.html

Bartuska, T. J., \& Young, G. (2007). The built environment: definition and scope. The Built Environment, 2, 3-14.

Bermudez, M. (2012). How does outdoor lighting cause light pollution. Del. Mar. Retrieved from https://www.delmarfans.com/educate/basis/lightingpollution

Brox, J. (2015). Out of the dark: A brief history of artificial light in outdoor spaces. Urban Lighting, Light Pollution and Society, New York, 13-29.

Cinzano, P., Falchi, F., \& Elvidge, C. D. (2001). The first world atlas of the artificial night sky brightness. Monthly Notices of the Royal Astronomical Society, 328(3). https://doi.org/10.1046/j.1365-8711.2001.04882.x

Crawford, D. L. (2001). Light pollution: Changing the situation to everyone's advantage. In Symposium-International Astronomical Union (Vol. 196, pp. 33-38). https://doi.org/10.1017/S0074180900163806

Darke, N. (2019). Our nights are getting brighter, and Earth is paying the price. National Geographic, Star Struck, April 2019. Retrieved from https: //www.nationalgeographic.com

Edwards, G. (2019). Multidisciplinary approach to environmental problems and sustainability. Encyclopedia of Sustainability in Higher Education. https://doi.org/10.1007/978-3-030-11352-0_241

Falchi, F., Cinzano, P., Elvidge, C. D., Keith, D. M., \& Haim, A. (2011). Limiting the impact of light pollution on human health, environment and stellar visibility. Journal of Environmental Management, 92(10), 2714-2722. https://doi.org/10.1016/j.jenvman.2011.06.029

Frumkin, H. (2008). Nature contact and human health, biophilic design. 
Gaston, K. J., Visser, M. E., \& Hölker, F. (2015). The biological impacts of artificial light at night: the research challenge. https://doi.org/10.1098/rstb.2014.0133

Gerrish, G. A., Morin, J. G., Rivers, T. J., \& Patrawala, Z. (2009). Darkness as an ecological resource: the role of light in partitioning the nocturnal niche. Oecologia 160. https://doi.org/10.1007/s00442-009-1327-8

Gritzner, C. F. (2010). Environment and natural resources. Infobase Publishing.

Haim, A., \& Zubidat, A. E. (2015). Artificial light at night: melatonin as a mediator between the environment and epigenome. Philosophical Transactions of the Royal Society. https://doi.org/10.1098/rstb.2014.0121

Hölker, F., Moss, T., Griefahn, B., Kloas, W., Voigt, C. C., Henckel, D., Franke, S. (2010). The dark side of light: a transdisciplinary research agenda for light pollution policy. Ecology and Society, 15(4). https://doi.org/10.5751/ES-03685-150413

Hussein, A. (2020). Slowly seeing the light: an integrative review on ecological light pollution as a potential threat for mollusks. Environ Sci Pollut Res, 28, 5036-5048. Retrieved from https://doi.org/10.1007/s11356-020-11824-7

Insulander, A. M. (2012). Light pollution consequences and sustainable lighting design. Swedish University of Agricultural Sciences. Land Scape Program. Retrieved from https://epsilon.sluse/

International Federation of Landscape Architects. (2003). IFLA News, no. 48, 2003. Retrieved from https://issuu.com/ifla_48_July

Kalavathy, S. (2004). Environmental studies. Tiruchirappalli, India: Bishop, Herber College.

Kane, S. (2016). These incredible maps show the most light-polluted places in the world. Tech Insider.

Karol, D., et al.. (2010). The effects of light pollution in Hong Kong. Worcester Polytechnic Institute (WPI), Friends of the Earth, project no. AGK-1004. Retrieved from https//:www.web.wpi.edu

Khan, A. (2017). Artificial lights are eating away at dark nights—and that's not a good thing.

Kronfeld-Schor, N., \& Dayan, T. (2003). Partitioning of time as an ecological resource. Annual Review of Ecology, Evolution, and Systematics, 34(1), 153-181. https://doi.org/10.1146/annurev.ecolsys.34.011802.132435

Kuhun, A., et al.. (2012). Through light we care. Zumtobel AG, corporate communications, AT-6850 Dornbirn. Retrieved from https://wwwthornlighting.com

Kumaraswamy, et al.. (2004). Constructional industry development. Journal of Sustainable Environment, 1.

Kyba, C. C., Kuester, T., De Miguel, A. S., Baugh, K., Jechow, A., Hölker, F., \& Guanter, L. (2017). Artificially lit surface of Earth at night increasing in radiance and extent. Science Advances, 3(11), e1701528. https://doi.org/10.1126/sciadv.1701528

Longcore, T., \& Rich, C. (2004). Ecological light pollution. Front Ecol Environ, 2(4), 191-198. https://doi.org/10.1890/1540-9295(2004)002[0191:ELP]2.0.CO;2

Mizon, B. (2002). Light pollution: responses and remedies, Light pollution: responses and remedies/Bob Mizon, Patrick Moore's Practical Astronomy Series. London: Springer.

Mizon, B. (2012). Light pollution: responses and remedies. Springer Science \& Business Media. https://doi.org/10.1007/978-1-4471-0669-2

Nader, M., et al.. (2012). Environmental resource monitoring in Lebanon-ERML. Institute of the Environment University of Balamand, Beirut-Lebanon. https://doi.org/10.1007/978-1-4614-3822-9

Narisada, K., \& Schreuder, D. (2004). Light pollution and astronomy. In Light pollution handbook (pp. 115-138). Springer, Dordrecht. https://doi.org/10.1007/978-1-4020-2666-9_5

National Geographic Society. (2015). The earth environmental spheres. Retrieved from https://www.nationalgeographic.com/adventure/article/150609

Neff, M. M., Fankhauser, C., \& Chory, J. (2000). Light: an indicator of time and place. Genes \& Development, 14(3), 257-271.

Ragni, M., \& D'Alcal'a, M. R. (2004). Light as an information carrier underwater. Journal of Plankton Research, 26, 433-443. https://doi.org/10.1093/plankt/fbh044

Rüdiger, G., \& Harald, H. (1992). Handbook of lighting design. 
Schreuder, D. A. (1995). Quality lighting - The need to cry over spilled milk. Paper presented at 3rd European Conference on Energy-Efficient Lighting, 18th-21st June 1995, Newcastle upon Tyne, England. Leidschendam, Duco Schreuder Consultancies, 1995.

Slade, J. (2018). Starring for Darkness. Illuminating, Engineering Society. Retrieved from https://www.ies.org/ida/starring

Stone, T. (2017). Light pollution: A case study in framing an environmental problem. Ethics, Policy \& Environment, 20(3), 279-293. https://doi.org/10.1080/21550085.2017.1374010

Taylor, M. A., \& Carper, K. L. (2007). The built environment: A collaborative inquiry into design and planning. Hoboken: John Wiley \& Sons.

The Encyclopedia Americana. (1918). A library of universal knowledge. New York. Encyclopedia Americana Corp.

\section{Copyrights}

Copyright for this article is retained by the author(s), with first publication rights granted to the journal.

This is an open-access article distributed under the terms and conditions of the Creative Commons Attribution license (http://creativecommons.org/licenses/by/4.0/). 